\title{
Refletindo Sobre Processos Educativos em Ambientes Virtuais à Luz da Biologia do Conhecer
}

\section{Reflecting on educational processes in virtual learning environments in the light of Knowledge Biology}

\begin{abstract}
Resumo: Apresentamos, em linhas gerais, a perspectiva teórica da Biologia do Conhecer, uma concepção de ambientes virtuais de aprendizagem e uma discussão a respeito da contribuição dessa teoria para entender os processos educativos que podem surgir nesses ambientes. Para tanto, são apresentados e discutidos conceitos desta abordagem, os quais fornecem sustentação teórica para concebermos ambientes virtuais como sistemas autopoiéticos e, portanto, vivos. Assim, são considerados os conceitos de cognição, de emoção e de linguagem, destacando que educar, pela perspectiva desse arcabouço teórico, é criar, realizar e validar na convivência um modo particular de conviver $\mathrm{Na}$ perspectiva das considerações apresentadas, conceber processos educativos mediados por ambientes virtuais de aprendizagem requer a configuração de espaços de convivência de modo que os atores do processo possam fluir juntos no conviver, numa história de interações recorrentes. Palavras-chave: Biologia do Conhecer. Processos educativos. Ambientes virtuais de aprendizagem.
\end{abstract}

Abstract: We present, in general lines, the theoretical perspective of Biology of Knowledge, a conception of virtual learning environments and a discussion regarding the contribution of this theory to understand the educative processes that can emerge in these environments. With this purpose, we present and discuss concepts of this approach that offer theoretical support to conceive virtual environments as autopoietic systems and, therefore, living systems. Thus, the concepts of cognition, emotion and language are considered, emphasizing that to educate, under the perspective of this theoretic framing, is to create, to carry through and to validate in the convivial gathering a particular way to live together. In the perspective of the considerations here presented, to conceive educative processes mediated by virtual learning environments requires the configuration of spaces for convivial gatherings in such a way that the actors of the process can partner, in a path of recurrent interactions.

Keywords: Biology of Knowledge. Educative processes. Virtual learning environments.

SOARES, Eliana Maria do Sacramento: $\mathrm{RECH}$, Jane. Refletindo Sobre Processos Educativos em Ambientes Virtuais à Luz da Biologia do Conhecer. Informática na Educação: teoria \& prática, Porto Alegre, v. 12, n. 2, p. 147-155, jul./dez 2009.

\author{
Eliana Maria do Sacramento Soares \\ Universidade de Caxias do Sul \\ Jane Rech \\ Universidade de Caxias do Sul
}

\section{Entendendo a Biologia do Conhecer}

A proposta deste artigo é apresentar ideias que suscitem reflexões sobre os processos educativos em ambientes virtuais, na perspectiva da Biologia do Conhecer (MATURANA; VARELA, 1995, 1997, MATURANA, 1997). Essa teoria constitui-se num arcabouço teórico que procura mostrar como os processos cognitivos humanos surgem da operação desses enquanto seres vivos. Como tal, ela envolve reflexões voltadas para a compreensão dos seres vivos, de sua história evolutiva, da natureza das explicações, da linguagem, daquilo que nos faz humanos. Como uma reflexão sobre como fazemos o que fazemos, ela se constitui numa epistemologia. Sendo, ao mesmo tempo, uma reflexão sobre como existimos enquanto seres que vivem na linguagem, ela se constitui no estudo das relações humanas.

Esta abordagem teórica ocupa-se da caracterização dos seres vivos a partir da dinâmica dos processos que os constituem e não com base no rol de suas propriedades ou de seus constituintes. Ou seja, o foco desta teoria está nas relações entre os constituintes do ser vivo 
e não na sua forma ou substância. Isso fica evidenciado quando esses autores escrevem:

O ser vivo não é um conjunto de moléculas, mas uma dinâmica molecular, um processo que acontece como unidade separada e singular como resultado do operar e no operar das diferentes classes de moléculas que a compõem, em um interjogo de interações e relações de proximidade que o especificam e realizam como uma rede fechada de trocas [grifo nosso] e sínteses moleculares que produzem as mesmas classes de moléculas que a constituem, configurando uma dinâmica que ao mesmo tempo especifica em cada instante seus limites e extensão. (MATURANA; VARELA, 1997, p. 15)

A essa rede fechada sobre si mesma, os autores chamam autopoiese. Partindo dessa concepção, eles definiram os seres vivos como sistemas autopoiéticos. Maturana e Varela (1997), no prefácio do livro De Máquinas e Seres Vivos, explica que cunhou o termo autopoiese, pois este lhe pareceu adequado para denominar a organização do ser vivo, da perspectiva que ele e Varela estavam concebendo. Auto significa si mesmo e se refere à autonomia dos seres vivos, que são autoorganizadores, e poiese, que compartilha da mesma raiz grega da palavra poesia e significa criação, construção. Assim, autopoiese significa autocriação, auto-organização do ser vivo ou dinâmica da autogeração. Por meio dessa noção, Maturana e Varela (1995, 1997) explicam a dinâmica da autocriação ou da auto-organização, que constitui a organização do ser vivo. Essa proposição teórica considera que a conservação da organização de um sistema vivo, estruturalmente acoplado ao meio onde existe, torna-se condição necessária a sua existência. Estruturalmente acoplado no sentido de que o sistema se modifica de forma congruente com o meio, em interações recorrentes, numa relação circular.

Sob esse ponto de vista, é a estrutura do ser vivo, entendido como um sistema formado por componentes, que determina seu espaço de existência, um espaço no qual ele opera em rede, enquanto unidade composta, ou, dito por outras palavras, enquanto unidade sistêmica, que pode ser perturbada pelas interações entre seus componentes. Nos processos autopoiéticos, é a estrutura que muda continuamente de estado, conservando sua organização em acoplamento com o meio. Então, para continuar vivo, o sistema necessita que sua estrutura, independente das mudanças/ perturbações/interações que ocorram, mantenha a organização. Caso isto não seja possível, o sistema se desintegra e morre. Deste modo, é a organização autopoiética que define o ser vivo como unidade sistêmica a partir das interações que estabelece. É o processo autopoiético que permite ao sistema produzir-se continuamente e determinar os seus limites. Assim, as transformações dinâmicas da unidade sistêmica, resultantes das interações que estabelece, produzem os próprios componentes da unidade que, por sua vez, conservam a organização, o que indica que as mudanças que surgem estão subordinadas à conservação da sua organização.

Dito de outra forma, a autopoiese, a essência da dinâmica constitutiva dos seres vivos, é composta por uma rede de processos de produção onde cada componente participa da produção e da transformação de outros elementos da rede. Como resultado, ou produto dessa coprodução de componentes, surge o padrão de organização do sistema vivo. Este, por sua vez, só poderá ser reconhecido como tal se estiver incorporado a uma estrutura física. Essa incorporação é um processo ininterrupto, que fica em andamento durante todo o viver de cada ser vivo. Há um fluxo incessante de energia e matéria através de um organismo vivo, o que permite o crescimento, o desenvolvimento e a evolução do sistema. Existe, então, em todo sistema vivo, um processo vital contínuo, incorporado a seu padrão organizacional e que liga os componentes da estrutura ao padrão que caracteriza sua organização. Dessa forma, falar de autopoiese é falar da organização dos seres vivos, na concepção explicativa de Maturana e Varela.

Essa noção pode ser utilizada também para compreender sistemas sociais: “tal organização [ ... . ] pode ser realizada em muitos domínios diferentes, com diferentes tipos de componentes, e dar origem, assim, a muitas classes diferentes de sistemas" (MATURANA; VARELA, 1997, p. 18). Esse ponto de vista fornece a sustentação teórica para pensarmos ambientes virtuais de aprendizagem como sistemas autopoiéticos ${ }^{1}$,

1 Embora inicialmente Maturana e Varela (1997a) tenham concebido a noção de autopoiese apenas para se referirem ao modo particular de organização dos seres vivos, com o avanço de seus estudos, eles passam a admitir que " tal organização [ . . . ] pode ser realizada em muitos domínios diferentes, com diferentes tipos de componentes". (MATURANA; VARELA, 1997a, p. 18), incluindo aí as diversas formas de sistemas sociais. É esse percurso teórico (que pode 
cuja reflexão é o foco principal deste artigo.

Dito isso, uma noção que interessa discutir aqui é a de cognição. Maturana e Varela (1995, 1997) apresentam uma concepção de cognição a partir das características dos seres vivos, destacando que elas determinam as interações do indivíduo com o meio. Assim, eles enfatizam que a cognição, e todos os fenômenos com os quais ela está relacionada, envolvem de maneira integral o indivíduo como um ser biológico. Os autores optam por um tipo de explicação da cognição ou, por suas próprias palavras, do conhecer, que faz referência ao processo histórico, dinâmico, contingente e recursivo do desenvolvimento dos seres vivos ao longo da sua ontogenia e que diz respeito à efetividade de seu viver ${ }^{2}$. Por outras palavras, não vivemos interações que especifiquem, de fora de nossa estrutura, o que podemos conhecer. Somos, ao contrário, seres históricos determinados por nossa estrutura biológica, que é uma estrutura plástica e dinâmica. $\mathrm{O}$ que distinguimos? O que conhecemos? Distinguimos e conhecemos aquilo que nossas histórias filogenética (a história da espécie) e ontogenética (a história do indivíduo, desde a sua concepção até sua morte) nos permite. Desse modo, é nossa estrutura biológica que nos possibilita viver certos tipos de mundo e não outros. Isso significa que os mundos que vivemos, conhecemos e experienciamos dependem do que nossas estruturas filo e ontogenética nos permitem. Também construímos nossos mundos passo a passo junto com outros seres vivos na convivência. Essa visão enfatiza a importância da experiência como forma de conhecimento.

Como seres vivos, vivemos simultaneamente dois domínios diferentes: o domínio da fisiologia (ou da dinâmica estrutural) e o domínio do comportamento ou das interações. Esses domínios são distintos, mas indissociáveis. Isso significa que, em nossas explicações (linguagem) sobre o que conhecemos, não podemos reduzir um domínio ao outro. Dessa forma, a linguagem, a cognição e a nossa con-

se melhor compreendido lendo Maturana e Varela (1997a), que nos autoriza a sustentar, nesse estudo, a concepção de ambientes virtuais de aprendizagem como sistemas autopoiéticos.

2 Aqui é importante esclarecer que a concepção de cognição pode ser fundamentada a partir de diferentes abordagens teóricas. Neste artigo, ela será entendida pela perspectiva da Biologia do Conhecer e, assim, entendida como sinônimo de conhecer. duta ao viver dependem da dinâmica de nossa fisiologia, mas não se reduzem a ela e nem a qualquer um de seus componentes:

a linguagem, sendo um fenômeno que nos envolve como seres vivos e, portanto, um fenômeno biológico que se origina na nossa história evolutiva, consiste num operar recorrente, em coordenações de coordenações consensuais de conduta. Disto resulta que as palavras são nós nas redes de coordenação de ações, e não representantes abstratos de uma realidade independente dos nossos afazeres. É por isto que as palavras não são inócuas e que não é indiferente usarmos uma ou outra numa determinada situação. As palavras que usamos não somente revelam o nosso pensar, como também projetam o curso do nosso fazer. Ocorre, entretanto, que o domínio em que se realizam as ações que as palavras coordenam não é sempre claro num discurso, e é preciso esperar o devir do viver para sabê-lo. [ . . . ] o conteúdo do conversar numa comunidade não é inócuo para esta comunidade, porque arrasta consigo seus afazeres. (MATURANA, 1999, p. 90, grifo nosso)

Temos, assim, um processo recursivo, no qual tudo o que fazemos no domínio de nossas interações depende da nossa fisiologia e é determinado, momento a momento, por nossa estrutura. Então, Maturana (1993, p. 31) concebe a aprendizagem "como um processo de adaptação, de acomodação a uma circunstância diferente daquela em que o organismo (estudante) se encontrava originalmente".

Esta proposição tem importantes consequências para entender a aprendizagem e a comunicação humanas. Em alguns domínios, os processos educativos são baseados apenas no discurso do professor, que instrui o estudante inserindo o conhecimento ou transferindo informações. Essa forma de pensar o processo de aprender não está alinhada à visão de cognição dos paradigmas educacionais em emergência. Por essa perspectiva, propomos que a Biologia do Conhecer pode auxiliar na mudança dessa visão, dando importantes contribuições para a reflexão do processo de aprendizagem, ajudando a ultrapassar a ideia de que aprender é ouvir discursos, para entender que aprender é realizar transformações, de dentro para fora.

Nesse contexto explicativo, as emoções são concebidas como elementos fundantes das relações sociais. Na visão de Maturana (1997), emoções são disposições/dinâmicas corporais que especificam âmbitos ou possibilidades de 
ações. Distintas emoções se diferenciam, exatamente porque especificam diferentes domínios de ações. Em decorrência disso, todas as nossas ações se fundamentam no emocional, o que significa que nada nos acontece, nada fazemos que não esteja definido como uma ação de certo tipo, a partir de uma emoção que a torna possível.

Maturana e Varela ${ }^{3}$ chamam atenção para a indissociabilidade dos processos de viver e conhecer, quando declaram que todo o ato de conhecer é uma ação efetiva que permite, a um ser vivo, continuar sua existência num mundo que ele mesmo faz surgir, na medida em que se esforça para conhecê-lo. Na visão do viver, enquanto construção de conhecimento a partir da vivência/experiência, esses autores destacam a importância do contexto, do ambiente e da emoção, no qual a pessoa está inserida. Eles afirmam que o conhecer é um fenômeno do operar do ser vivo, em congruência com sua circunstância.

Essa perspectiva teórica mostra a necessidade de se considerar a individualidade da pessoa em determinada situação. No momento em que se atribui importância ao indivíduo, que se respeita sua legitimidade e que se compreendem seus limites, valorizam-se as suas circunstâncias. Por outro lado, essa teoria também faz referência à condição sistêmica que une o indivíduo e a sociedade. Ao mesmo tempo que reconhece que os indivíduos, em suas interações, constituem o social, ela enfatiza que o social é o meio em que os indivíduos se realizam como indivíduos. Dessa forma, em sentido estrito, não existe contradição entre o individual e o social, porque ambas as instâncias são mutuamente gerativas. Associado ao entendimento da circunstância e ao respeito pelo indivíduo que é constituído pelo e constitui o social, essa teoria destaca a importância da linguagem e da emoção, que, nesse domínio teórico, estão unidas sob a denominação de conversar. Maturana sustenta:

O humano é vivido no conversar, no entrelaçamento do linguajar e do emocionar que é o conversar. Além disso,

3 Em vários trechos desse texto, ora nos referimos a Maturana e ora nos referimos a Maturana e Varela, por uma questão de reconhecimento a Varela, pois o desenvolvimento da chamada Biologia do Conhecer emerge de discussões e elaborações conceituais de ambos, embora, depois, cada um deles tenha seguido diferentes desdobramentos teóricos. o humano se vive em redes de conversações que constituem culturas, e também se vive nos modos de vida que as culturas constituem como dimensões psíquicas, espirituais ou mentais. (MATURANA, 1997, p. 121)

Essa afirmação valida a noção de educar proposta por Maturana (2002, p. 147), para quem: Educar é criar, realizar e validar na convivência um modo particular de conviver. Isso sempre se realiza em uma rede de conversações que coordena o fazer e o emocionar dos participantes. Para ele:

Estudar é conviver. O estudante se transforma na convivência com o professor ou professora. O ou a estudante é aquele ou aquela que aceita o convite de outro para conviver transitoriamente com ele ou ela em um certo espaço de existência em que esta pessoa tem mais habilidade de ação e reflexão. Para isto, estudante e professor devem aceitar-se mutuamente como legítimos outros em convivência. (MATURANA, 2002, p. 152)

Moraes, apresentando a idéia de cognição, com base na Biologia do Conhecer, afirma que:

a cognição - o processo de conhecer - é muito mais amplo do que a concepção do pensar, raciocinar e medir, pois envolve a percepção, a emoção e a ação, tudo que constitui o processo da vida, como elementos fundamentais constitutivos da dinâmica da vida. (MORAES, 2003, p. 47)

Essa autora chama atenção para o caráter dinâmico e auto-organizador dos processos cognitivos próprios dos seres vivos, enfatizando que a cognição diz respeito ao processo histórico, dinâmico, contingente e recursivo do desenvolvimento dos seres vivos, o que dá destaque à experiência e à convivência como formas de conhecimento, entretecidas pela linguagem e pelas emoções (o conversar).

\section{Ambientes Virtuais: possíveis espaços de aprendizagem}

A expressão ambientes virtuais de aprendizagem tem sido utilizada, de modo geral, para referir-se ao uso de recursos digitais de comunicação, utilizados para mediar a aprendizagem. O entendimento de ambiente aqui considerado, vai além da ideia de um conjunto de páginas educacionais na Web ou de sites com diferentes ferramentas de comunicação e de informação. Entendemos que ambientes 
virtuais de aprendizagem são espaços sociais, constituindo-se de interações sociocognitivas sobre ou em torno de um objeto de estudo ou de construção: espaços na Web, concebidos como cenários onde as pessoas interagem, convivem, mediadas pela linguagem hipermidiática, cujos fluxos de comunicação entre os interagentes são possibilitados pela interface gráfica/digital. Nesse sentido, o foco não é a interface em si mesma, mas o quê os interagentes fazem com essa interface e o quê essa interface faz com os interagentes. Assim, o plano pedagógico que sustenta a concepção e configuração do ambiente é fundamental para que ele possa ser um espaço onde os interagentes se construam como elementos ativos, co-autores do processo de aprendizagem, fazendo emergir uma rede de comunicação, que pode levar os interagentes a construírem e a se transformarem conjuntamente na convivência nesse ambiente.

Dessa forma, o que é mais específico nos ambientes virtuais ${ }^{4}$ de aprendizagem assim concebidos é o fluxo de comunicação, expresso nos registros das diferentes ferramentas. Sob esse entendimento, esse fluxo é o meio do estar juntos, nesses ambientes, de forma que os interagentes não estejam restritos apenas ao uso das informações dos ambientes ou da Web. Eles se tornam produtores de informação, eles entram no jogo.

A partir dessa concepção de ambiente virtual de aprendizagem, podemos considerar os conceitos da Biologia do Conhecer, para conceber esses ambientes como sistemas vivos, entendendo-os a partir das relações entre seus constituintes e não apenas a partir de seus constituintes, sua forma e sua substância. Para isso, inicialmente, podemos pensar neles como sistemas, entendidos de forma ampla como espaços de convivência entre estudantes e professores. Nesses espaços, podem surgir fluxos de comunicação e múltiplas produções, frutos de intervenções e de estratégias pedagógicas realizadas pelo professor, ou pelos estudantes, com padrões específicos de organização. Diferentes ambientes podem ser configurados de tal forma que apresentem um padrão de

4 Aqui o termo virtual especifica o contexto no qual este artigo foca suas reflexões, mas as contribuições desta abordagem também são úteis para a compreensão dos processos que ocorrem em ambientes nos quais a aprendizagem é presencial. organização (configuração de relações entre seus constituintes) autopoiético e, assim, ser concebidos como ambientes vivos. Para tanto, eles precisam ser modificados pela ação de seus interagentes (estudantes e professores) e modificados de forma congruente, numa relação circular e autopoiética. Por essa perspectiva, os ambientes podem ser considerados como espaços de convivência que possibilitam a vida. Como na Biologia do Conhecer, viver é aprender, pode-se considerar a vida nos ambientes virtuais como aprendizagem. Nesse sentido, a vida seria o resultado de transformações em um meio particular, numa forma específica, através de interações recorrentes.

Sob esse enfoque, pensar o processo de aprendizagem é configurar um espaço de convivência, de modo que professores e estudantes possam fluir juntos no conviver, numa história de interações recorrentes. Sob esse olhar, o professor convive com o estudante, numa circunstância, transformando e transformando-se em interações recorrentes. Nesse cenário, podemos considerar que a estrutura (aqui entendida no sentido da Biologia do Conhecer, enquanto um conjunto de componentes e as relações efetivas entre eles, ao comporem um sistema autopoiético) é formada pela interface tecnológica, pelas tarefas propostas, pelo objeto do conhecimento, etc. A organização (ou o padrão de organização) é a forma como o grupo interagente se apropria do ambiente e se relaciona em torno do objeto de conhecimento, gerando um conjunto recorrente e peculiar de interações que o diferencia de outro ambiente, mesmo que este tenha se organizado em torno do mesmo objeto de conhecimento. Assim, podemos considerar que determinado ambiente é autopoiético, é vivo, quando sua estrutura muda, mas se conserva o padrão de organização que o caracteriza. Isso implica que o padrão de organização autopoiético, que caracteriza determinado ambiente, tornando-o único, é capaz de gerar a si próprio, a partir das relações entre seus componentes, criando o que Maturana chama de vida. Vida essa sustentada por interações recorrentes, por conversações, por transformações na conduta dos interagentes, pela ênfase na autoria, pela autorresponsabilidade e pelo interesse do estudante que interroga e investiga independentemente da cobrança do professor.

O ambiente, por meio de sua interface gráfica (ferramentas de comunicação, imagens, 
links, etc.) e das relações que são estabelecidas entre os interagentes (professores e estudantes com suas respectivas histórias e estruturas), que se manifestam pela linguagem (conversas) permeadas pelo objeto de conhecimento, formam um sistema, onde cada um desses elementos pode ser considerado uma unidade. Os fluxos recorrentes das conversações que podem emergir nesse contexto constituem a energia do sistema, a qual, estando em constante circulação, gera e regenera o próprio sistema, por meio das ideias e da criatividade. Nessa perspectiva, a aprendizagem surge desses fluxos, alimentando e sendo alimentada por eles, em movimentos autopoiéticos. Nesse sentido, cada elemento se modifica e é modificado concomitantemente, em um movimento circular contínuo, a partir da convivência.

Tomemos como exemplo o fórum de discussão de um ambiente virtual de aprendizagem, que registra a conversação entre estudantes sobre um tema em discussão. Por mais que ele (fórum) contenha fluxos recorrentes de comunicação, o que ocorrerá com os estudantes depende do que a estrutura particular de cada um deles der de sentido para esses fluxos, e somente ela pode determinar transformações e aprendizagens. Nas palavras de Maturana:

Os seres vivos são sistemas determinados estruturalmente e tudo o que se passa com eles a cada instante, resulta de sua dinâmica estrutural e é determinada por ela, de maneira que os objetos externos podem somente desencadear mudanças estruturais determinadas pela própria estrutura dos seres vivos. E o viver é uma história na qual o curso das mudanças estruturais que se vive é contingente à história de interações pelo encontro com os objetos (externos). E nessa história o ser vivo e sua circunstância mudam juntos. (MATURANA, 1993 , p. 31)

O mesmo pode ser pensado em relação a cada um dos espaços de um ambiente de aprendizagem. O sentido que será dado para as orientações, as tarefas e a outras ações desenvolvidas é determinado pela dinâmica estrutural que se estabelece entre os estudantes (interagentes) e a configuração do ambiente. Dinâmica essa, constituída de operações recorrentes, a partir das quais o ambiente pode ganhar vida, baseado nos fluxos de convivência que vão sendo desenvolvidos. Isso é o que Moraes (2003) denomina rede de aprendiza- gem, se referindo às contínuas mudanças estruturais que podem ocorrer em ambientes de aprendizagem, entendidos como sistema vivo.

Assim, estudantes e professores, enquanto interagentes nesses ambientes, concebidos como sistemas vivos, podem ser entendidos como seres que vivem na linguagem, ou, nas palavras de Maturana, no conversar. E é através desse conversar que professores e estudantes se tornam cocriadores desses ambientes. Assim, as possíveis modificações que acontecem nas estruturas dos interagentes são o resultado do operar desses, em acoplamento, no domínio de ação, no caso, o ambiente, por meio de interações recorrentes.

O ambiente não é apenas um meio a partir do qual ocorre a aprendizagem, mas, na concepção que propomos, ele é algo constitutivo do próprio processo de aprendizagem.

Conforme Maraschin e Axt (2005, p. 40), é possível que "as tecnologias não sejam apenas meios para aprender, conhecer, mas sejam constitutivas dos próprios modos de conhecer, de aprender". Mas, para isso, "é necessário não tomá-las somente como princípios explicativos das possibilidades de significação, mas pensálas como resultado do próprio mecanismo do viver e de produção de sentido" (MARASCHIN; AXT, 2005, p. 40).

Nesse contexto, os observáveis da aprendizagem são as mudanças e transformações estruturais que podem decorrer desses fluxos de conversações recorrentes. Esses observáveis podem aparecer na forma de mudanças de conduta ou nos registros ${ }^{5}$ (linguagem) publicados nos diversos espaços do ambiente. O modo de se expressar nos registros é, ao mesmo tempo, individual e coletivo. Sua configuração particular, em termos de redes ou sistema de relações estabelecidas entre seus integrantes, e manifesta nos textos do ambiente, é que permite identificá-lo como sendo o ambiente de um dado processo educativo e não de outro.

O ambiente, concebido como um sistema que opera em rede, pode ser perturbado pelas interações entre os estudantes e o professor que o acessam, mas precisa se reorganizar mantendo sua coerência estrutural, no sentido

5 Registros aqui são entendidos como os textos postados pelos interagentes do ambiente virtual de aprendizagem, em seus diferentes recursos de comunicação. 
de manter a vida que o constitui, ou, no caso de não conseguir, ou não querer fazer isso, deixá-la se extinguir. Dito de outra forma, se a estrutura do ambiente de aprendizagem não mantém a organização, o ambiente morre, ou seja, com a diminuição ou a inexistência de interações que levem a trocas significativas nos diversos espaços do ambiente (fórum, chat, webfólio), naturalmente ele entra em processo de entropia, até chegar ao ponto de desconstituir-se enquanto espaço de aprendizagem.

Nesse sentido, é oportuno destacar a importância da atuação do professor ou de um moderador, que muitas vezes surge num movimento autopoiético como um facilitar do processo de vivificação do ambiente, a partir de perguntas, problematizações e sistematizações, que possam organizar e fomentar novas ideias e práticas, estimulando e sustentando os fluxos recorrentes de conversação. Como exemplo, podemos considerar que cada interagente, estudante ou professor, que participa de um fórum, pode colaborar com a produção e a transformação de todo o fórum, bem como contribuir com as transformações que podem ser operadas nos integrantes durante a convivência nesse espaço. Dito de outra forma, entendemos os participantes do fórum como seres vivos convivendo em interações recorrentes. Se, nesse contexto houver a conservação de sua organização, enquanto seres vivos, ou seja, se eles conservarem suas formas de expressão como unidades particulares em congruência com os fluxos de interação nos quais estão vivendo, podem surgir histórias de transformações estruturais. Essa existência em interações recorrentes, em uma circunstância, é o que Maturana chama deriva. Assim, podemos pensar nos estudantes e professores, existindo em uma história de modificações estruturais sob interações recorrentes com sua circunstância (no caso, o fórum), em condições de conservação de sua organização, a qual os define como seres vivos.

É importante destacar que as considerações apresentadas estão em consonância com resultados de pesquisas sobre aprendizagem em ambientes virtuais, que relacionam o uso das tecnologias digitais na educação e os processos de aprendizagem como emergência da convivência nestes ambientes. Valentini (2003) investiga os processos de interação, num ambiente virtual de um curso de graduação, buscando compreender como são constituídas as trocas cooperativas suportadas por essas interações. Os resultados desse estudo indicam a constituição de redes que expressam movimentos de auto-organização dos interagentes. A autora destaca as tarefas convergentes como uma estratégia que favorece as trocas comunicativas, num movimento de descentração e de auto-organização.

Laurino-Maçada (2001), na sua tese de doutorado, focada na formação de professores e no uso de tecnologias, apresenta os AVAs como possibilidades de organização em uma ecologia cognitiva digital, cujo foco central de operação se dá no acoplamento entre sistemas que estruturam o espaço educacional: indivíduos, recursos digitais, formas de interação e proposta educacional. O estudo mostra que, em tais ambientes de aprendizagem, a dinâmica de funcionamento emergiu no decorrer das próprias interações dos participantes com o AVA, e desses entre si, numa re-atualização de relações diferenciadas. Isto possibilitou à comunidade tornar-se ativa em seu próprio processo de desenvolvimento, criando dinâmicas particulares de funcionamento em um constante movimento oscilatório.

Carneiro (2003) apresenta sua visão sobre os processos comunicacionais que se estabelecem em ambientes de aprendizagem envolvendo tecnologias. Os mapas das interações, gerados a partir da análise dos registros do ambiente virtual estudado, mostram fluxos de comunicação que se estabelecem como resultados de acoplamentos tecnológicos e sociais que ali acontecem. A autora identifica oscilações que surgem nas trocas comunicacionais ao longo do tempo, mostrando que as emoções envolvidas nos processos comunicativos determinam a passagem de um domínio comunicacional para outro.

Beiler (2004) mostra que a aprendizagem pode ser gerada a partir do operar em redes de conversação analisando as coordenações consensuais de ações registradas em fóruns de ambientes virtuais de aprendizagem. A referida pesquisadora estuda a rede conversacional, constituída no fórum de uma disciplina de determinado curso, buscando identificar coordenações consensuais de ações através do desenvolvimento de uma proposição explicativa que permite analisar os modos de operar das mensagens dos integrantes da comunidade. Maraschin e Axt (2005) sustentam a idéia de que as redes conversacionais, suportadas por 
tecnologias da informação e da comunicação, podem facilitar interações de reconhecimento e convivência com modos de viver e pensar distintos dos tomados como próprios, ampliando a possibilidade de produção de deslocamentos dos pontos de vista dos participantes. Elas destacam que:

a participação em redes telemáticas de conversação convoca a constituição recursiva de um plano de tensão entre diferentes modos de expressão, ação e significação. A necessidade de se auto-narrar para dar-se a conhecer em um coletivo pode promover efeitos de inclusão e de autoria. (MARASCHIN; AXT 2005, p. 142)

Elas citam investigações, tendo como foco de estudo, as redes de conversações presentes nas interações que surgem em ambientes digitais: Axt e Maraschin (1997, 1999), EideIwein (2001), Maçada (2001), Mazzochi (2001) e Carneiro (2003).

Esses referenciais destacam que o aporte teórico da Biologia do Conhecer, em seus diferentes recortes, pode ser útil para compreender/explicar os fluxos de comunicação que podem emergir em AVAs. As reflexões desse artigo, compartilhando da mesma base teórica, pretendem oferecer subsídios teóricos, no sentido de compreender de que modo a convivência, entendida nessa abordagem teórica, pode operar transformações estruturais, convergindo para a construção da aprendizagem. Essa construção está relacionada não apenas à configuração dos diferentes espaços e recursos do ambiente virtual, mas também à concepção de uma base teórica para a intervenção e gestão pedagógica nesses ambientes.

\section{Considerações Finais}

Frente às considerações desenvolvidas ao longo do texto, cabe perguntar: para que ocorra uma história de interações recorrentes, de acoplamento estrutural entre estudantes e professores, num ambiente de aprendizagem, o que precisa acontecer? As interações precisam ser construtivas, no sentido de preservação da organização do ambiente. Se isso não acontece, o organismo (nesse caso o ambiente) se desestrutura como sistema vivo. Isso significa que, se as interações forem de negação do outro, elas podem levar ao afastamento dos interagentes ( no sentido de que se não há interações, eles deixam de existir/interagir no espaço de convivência) e à desestruturação do ambiente virtual de aprendizagem. Para que haja interações recorrentes, o outro precisa ser visto como legítimo outro, na convivência. I sso é o oposto de negar e/ou julgar o outro, o que não significa que não possam ocorrer interações recorrentes na negação e na disputa, na discussão e no enfrentamento. A conduta de interações que aceita o outro na convivência é caracterizada por interações que denotam respeito e aceitação do outro, em seu espaço de existência e que denotem aceitação do outro em sua dignidade e legitimidade. Assim, se convivermos num domínio de violência e de controle, aprendemos a operar dessa e nessa forma, e daí criamos um mundo, com essas características. Ao contrário, se convivermos num mundo com operações de respeito mútuo, criamos ou fazemos emergir domínios de respeito, de tolerância e de fraternidade.

Na perspectiva dessas reflexões, pensar a aprendizagem no cenário dos ambientes virtuais de aprendizagem requer a configuração de espaços de convivência, de modo que os atores do processo possam fluir juntos no conviver, numa história de interações recorrentes. Dito de outro modo, a tarefa do professor é conviver com o estudante, numa circunstância, transformando e transformando-se em interações recorrentes.

Nesse caso, o ambiente se constitui numa circunstância para se viver no fazer e no refletir sobre o fazer, de modo que, por meio do viver em interações recorrentes, professores e estudantes possam se tornar diferentes, possam se transformar, no sentido de que eles venham a agir (conduzir-se) de forma diferente da qual agiam (se conduziam) antes.

Ao que tudo indica, estamos falando de uma rede cognitiva que pode ser sustentada e potencializada nos ambientes virtuais de aprendizagem, entendidos a partir da perspectiva aqui apresentada. Nesse sentido, fluxos de interações que facilitem a convivência nesses ambientes, a partir de operações recorrentes de respeito mútuo, fazem emergir espaços de respeito, de tolerância e de fraternidade. A partir dessa perspectiva, podemos inferir que, ao educar com base no respeito mútuo e na convivência em espaços de respeito e de fraternidade, estaremos educando para a Paz. 


\section{Referências}

BEILER, A. A Produção de Redes de Conversação Como Base à Aprendizagem. 2004. Tese (Doutorado em Informática na Educação) - Faculdade de Educação, Departamento de Psicologia, Instituto de Informática, Universidade Federal do Rio Grande do Sul, 2004, Porto Alegre, BR-RS.

CARNEIRO, M.L.F. O Acoplamento Tecnológico e a Comunicação em Redes. 2003. Tese (Doutorado em Informática na Educação) - Faculdade de Educação, Departamento de Psicologia, Instituto de Informática, Universidade Federal do Rio Grande do Sul, 2003, Porto Alegre, BR-RS.

LAURINO-MAÇADA, D. Rede Virtual de Aprendizagem: interação em uma ecologia digital. 2001. Tese (Doutorado em Informática na Educação) - Faculdade de Educação, Departamento de Psicologia, Instituto de Informática, Universidade Federal do Rio Grande do Sul, 2001, Porto Alegre, BR-RS.

MARASCHIN, C.; AXT, M. Acoplamento Tecnológico e Cognição. In: VIGNERON, J.; OLIVEIRA, V.B. de (Org.). Sala de Aula e Tecnologias. São Bernardo do Campo: Universidade Metodista de São Paulo, 2005. P. 39-51.

MATURANA, H. Uma Nova Concepção de Aprendizagem. Dois Pontos: teoria \& prática em educação, Belo Horizonte, v. 2, n. 15, p. 28-35, 1993.

MATURANA, H. A Ontologia do Conversar. In: MATURANA, H.; MAGRO, C.; GRACIANO, M.; VAZ, N. (Org.). A Ontologia da Realidade. Belo Horizonte: Ed. UFMG, 1997. P. 123-182.

MATURANA, H. Emoções e Linguagem na Educação e na Política. Belo Horizonte: Editora da UFMG, 1999.

MATURANA, H. Transformación en la convivencia. Santiago do Chile: Dolmen Ed., 2002.

MATURANA, H.; VARELA, F. A Árvore do Conhecimento: as bases biológicas do entendimento humano. São Paulo: Ed.I Psy II, 1995.

MATURANA, H.; VARELA, F. De Máquinas e Seres Vivos: Autopoiese: a organização do vivo. Porto Alegre: Artes Médicas, 1997.

MORAES, M.C. Educar na Biologia do Amor e da Solidariedade. Petrópolis (RJ): Vozes, 2003.

VALENTINI, C.B. Tecendo e Aprendendo: redes sociocognitivas e autopoiéticas em ambientes virtuais de aprendizagem. 2003. Tese (Doutorado em Informática na Educação) - Faculdade de Educação, Departamento de Psicologia, Instituto de Informática, Universidade Federal do Rio Grande do Sul, 2003, Porto Alegre, BR-RS.

Recebido em agosto de 2009

Aprovado para publicação em setembro de 2009

\section{Eliana Maria do Sacramento Soares}

Professora do Centro de Ciências Exatas e Tecnologia e do Programa de Pós-graduação em Educação, Mestrado em Educação, da Universidade de Caxias do Sul, UCS-RS - email: emsoares@ucs.br 